\title{
STUDI KELAYAKAN MAKAM KERAMAT AGUNG PEMECUTAN SEBAGAI DAYA TARIK WISATA PILGRIM DI DENPASAR (ANALISIS ASPEK PASAR DAN PEMASARAN)
}

\author{
Ashmi Hudaningsih \\ Ni Made Oka Karini \\ Luh Gede Leli Kusuma Dewi \\ Email : ashmihudaningsih@yahoo.com \\ PS. S1 Industri Perjalanan Wisata \\ Fakultas Pariwisata UNUD
}

\begin{abstract}
Makam Keramat Agung Pemecutan is one of the pilgrim tourism potentials in Denpasar. To avoid stagnant or decline position of Makam Keramat Agung Pemecutan development as a pilgrim tourist attraction, it is necessary to do a feasibility study. The most important and first aspect in feasibility study is market and marketing aspects.This study aims to determine the feasibility of market and marketing aspects of Makam Keramat Agung Pemecutan wich views from the market potential and the position of Makam Keramat Agung Pemecutan compared with its competitors, and make the right marketing strategy for Makam Keramat Agung Pemecutan in its development into a pilgrim tourist attraction.

The results of this study shows that potential market of Makam Keramat Agung Pemecutan is domestic tourists who are Muslims. From the analysis of the competitive profile matrix shows Makam Keramat Agung Pemecutans position more competitive than its competitors. Therefore, Makam Keramat Agung Pemecutan is feasible on the market and marketing aspects.

The suggestions provided are should establish management organization, make promotional activities, add facilities, and maintaining product quality of Makam Keramat Agung Pemecutan, continue this research about feasibility of Makam Keramat Agung Pemecutan in the other aspects especially culture aspect.
\end{abstract}

Keywords: Feasibility Study, Market Potential, Competitor Analysis, Pilgrim Tourist Attraction.

\section{PENDAHULUAN}

$\begin{array}{cccc}\text { Pola hidup } & \begin{array}{c}\text { masyarakat } \\ \text { berorientasi }\end{array} & \text { yang } \\ \text { pada }\end{array}$ materialistik menimbulkan semakin kompleksnya masalah yang dihadapi. Hal tersebut dapat membuat masyarakat jenuh pada rutinitas yang dijalani setiap hari sehingga muncul kebutuhan untuk mencari ketenangan. Wisata pilgrim yang dulu dianggap hanya berkaitan dengan agama tertentu dan tidak memiliki nilai jual, kini dapat menjadi alternatif untuk memenuhi kebutuhan tersebut.

Bali merupakan salah satu destinasi wisata di Indonesia yang paling banyak diminati oleh wisatawan domestik maupun mancanegara. Selain memiliki potensi wisata alam, budaya, dan hiburan, Bali juga menyimpan beberapa potensi wisata pilgrim. Adapun beberapa wisata pilgrim yang kini mulai berkembang adalah makam-makam tokoh Islam yang ada di Bali.

Telah banyak wisatawan yang mengunjungi makam-makam tersebut. Mayoritas wisatawan yang berkunjung menggunakan jasa dari travel agent. Beberapa travel agent di Bali ataupun di luar Bali telah mengemas potensi tersebut ke dalam sebuah paket wisata yang disebut ziarah wali pitu Bali.

Beberapa makam tokoh Islam yang termasuk dalam paket Ziarah Wali Pitu tersebut adalah pertama makam Mas Sepuh Raden Amangkuningrat di Kabupaten Badung, 
kedua makam Habib Umar Bin Maulana Yusuf Al Magribi di Tabanan, ketiga makam Habib Ali Bin abu Bakar Bin Umar Bin Abu Bakar Al Khamid di Klungkung, keempat makam Habib Ali Zaebal Abidin Al Idrus di Karangasem, kelima makam Syech Maulana Yusuf Al Baghdi Al Magribi di Karangasem, keenam makam The Kwan Lie di Buleleng, ke tujuh makam Habib Ali Bin Umar Bin Abu Bakar Bafaqih di Jembrana.

Selain mengunjungi ketujuh makam di atas wisatawan juga di ajak berkunjung ke makam Raden Ayu Siti Khotijah yang dikenal dengan nama Makam Keramat Agung Pemecutan.

Fasilitas yang tersedia di Makam Keramat Agung Pemecutan masih sangat terbatas. Sistem pengelolaan yang ada juga masih sangat sederhana.

Meskipun tidak menjadi daya tarik utama dalam paket ziarah wali pitu serta pengelolaannya masih sederhana dan fasilitas yang tersedia masih terbatas, tidak sedikit wisatawan yang berkunjung ke Makam Keramat Agung Pemecutan.

Melihat potensi yang dimiliki dan jumlah kunjungan wisatawan yang ada maka terdapat kemungkinan untuk mengembangkan Makam Keramat Agung Pemecutan sebagai daya tarik wisata pilgrim. Namun sebelum dikembangkan menjadi daya tarik wisata, maka perlu diadakan studi kelayakan bisnis untuk mengetahui layak atau tidak makam Keramat Agung Pemecutan dijadikan sebagai daya tarik wisata Pilgrim.

Untuk menilai kelayakan tersebut diperlukan penelitian pada beberapa aspek, salah satunya adalah aspek pasar dan pemasaran. Pada penelitian ini akan dilakukan studi kelayakan aspek pasar dan pemasaran Makam Keramat Agung Pemecutan untuk mengetahui peluang pasar serta posisi persaingan Makam Keramat Agung Pemecutan sehingga dapat dinyatakan layak atau tidak untuk dikembagkan menjadi sebuah daya tarik wisata.

\section{TINJAUAN PUSTAKA \\ Tinjauan Tentang Studi Kelayakan}

Sebelum menjalankan sebuah bisnis perlu diadakan studi kelayakan. Menurut Kasmir (2003) studi kelayakan merupakan sebuah pembelajaran secara mendalam tentang sebuah bisnis untuk menyatakan kelayakan dari bisnis tersebut.
Subagyo (2007) membagi aspek-aspek studi kelayakan menjadi dua bagian yaitu aspek primer (aspek pemasaran, aspek teknis, aspek manajemen, dan aspek ekonomi atau keuangan) dan aspek skunder (aspek lingkungan dan aspek sosial).

\section{Tinjauan Tentang Aspek Pasar dan Pemasaran}

Suratman (2001) dan Zubir (2006) menyatakan bahwa aspek pasar dan pemasaran merupakan aspek utama dan pertama yang harus dikaji dalam studi kelayakan bisnis.

Kasmir (2003) menyebutkan bahwa dalam aspek pasar dan pemasaran ini harus terlebih dahulu mengetahui peluang pasar dan analisis pesaing untuk menentukan kedudukan usaha yang akan dibuat, kemudian baru ditentukan strategi pemasaran.

\section{Tinjauan Tentang Wisata Pilgrim}

Menurut Pendit (1994) secara umum wisata pilgrim merupakan suatu jenis wisata yang dikaitkan dengan agama, sejarah, adat istiadat dan kepercayaan umat, seseorang atau kelompok.

\section{METODE PENELITIAN}

Penelitian ini dilakukan di Makam Keramat Agung Pemecutan jl. Batu Karu Monang Maning - Denpasar. Penelitian ini menggunakan metode pengumpulan data dengan wawancara dan kuesioner. Penentuan informan pada wawancara menggunakan metode purposive sampling.

Sedangkan untuk penyebaran kuesioner menggunakan metode purposive sampling dan accidental sampling dengan ukuran sampel menggunakan model J Supranto yaitu jumlah indikator dikalikan lima. Sampel untuk kuesioner segmentasi pasar dipilih dengan metode accidental sampling, jumlah indikator pada kuesioner ini adalah 11 kemudian dikalikan 5, maka jumlah responden adalah 55 responden. Sedangkan untuk kuesioner rating faktor strategi eksternal dan faktor strategi internal responden dipilih dengan metode purposive sampling. Dengan jumlah responden sebanyak 75 orang untuk kuesioner rating faktor strategi eksternal, dan 90 responden untuk kuesioner rating strategi internal. Terdapat tiga operasional variabel dalam penelitian ini yaitu potensi pasar, analisis pesaing, dan strategi pemasaran. Analisis yang 
digunakan adalah analisis deskriptif kuantitatif.

\section{HASIL \& PEMBAHASAN Potensi Pasar}

Salah satu penyebab peningkatan jumlah kunjungan wisatawan ke Makam Keramat Agung Pemecutan ini adalah adanya budaya berziarah ke makam-makam nabi, ulama, kyai, pahlawan ataupun keluarga yang dilakukan oleh umat Islam, didukung dengan adanya beberapa travel agent yang mengemas Makam Keramat Agung Pemecutan ke dalam paket ziarah wali pitu Bali yang kini telah menjadi tren di kalangan masyarakat khususnya umat Islam. Hal tersebut dapat dibuktikan dengan didominasinya kunjungan wisatawan ke Makam Keramat Agung Pemecutan oleh wisatawan beragama Islam dengan presentase sebesar $100 \%$.

Makam Keramat Agung Pemecutan lebih kompetitif dibandingkan dengan ketiga pesaingnya. Makam Keramat Agung Pemecutan dan Makam Keramat Pantai Seseh memiliki segmen pasar yang sama yaitu wisatawan dari berbagai agama dengan tujuan spiritual.

Keempat daya tarik tersebut mempunyai produk yang sama yaitu sebuah makam. Makam Keramat Agung Pemecutan memiliki sejarah yang unik dan merupakan satu-satunya makam perempuan muslim yang dikeramatkan di Bali. Arsitektur makam yang mengandung unsur-unsur budaya Bali, adanya pohon yang tumbuh dari dalam makam, dan adanya bendabenda peninggalan berupa tusuk konde Raden Ayu Siti Khotijah dan guci pemberian Raden Ayu Siti Khotijah untuk nenek Jro Mangku I Made Puger (juru kunci). Namun fasilitas dan sarana masih sangat kurang. Di Makam Keramat Agung Pemecutan hanya terdapat satu toilet, satu tempat wudhu, satu ruang juru kunci, satu pendopo, dan satu lemari kecil berisi Al-Qur'an dan beberapa buku do'a. Tidak tersedia pula tempat parkir khusus untuk wisatawan yang berkunjung.

Makam Keramat Pantai Seseh juga memiliki arsitektur bangunan yang bernuansa budaya Bali. Desa adat juga berperan dalam pengelolaan Makam Keramat Pantai Seseh sebagai sebuah daya tarik wisata, desa adat setempat mengelola area parkir untuk wisatawan yang berkunjung ke Makam Keramat Pantai Seseh. Di area parkir tersebut terdapat pos penjaga parkir, penyewaan kain
Hal tersebut memberikan peluang pasar bagi Makam Keramat Agung Pemecutan sebagai daya tarik wisata pilgrim. Keadaan demografis Indonesia yaitu terjadinya pertumbuhan penduduk Indonesia yang semakin meningkat per tahunnya dan mayoritas beragama Islam juga akan mendukung tersedianya potensi pasar bagi Makam Keramat Agung Pemecutan.

\section{Analisis Competitive Matrix Profile (CMP)}

Yang menjadi pesaing bagi Makam Keramat Agung Pemecutan adalah beberapa makam tokoh Islam yang juga dikeramatkan di Bali dan sudah banyak dikunjungi oleh wisatawan.Adapun beberapa makam tersebut adalah Makam Keramat Pantai Seseh yaitu Makam Raden Mas Sepuh Amangkuningrat, Makam Keramat Loloan Negara, dan Makam Keramat Karang Rupit.

selendang untuk wisatawan yang akan memasuki makam, toilet, serta beberapa toko makanan dan minuman.

Semua daya tarik tersebut memiliki harga yang kompetitif, wisatawan yang berkunjung ke daya tarik tersebut tidak dikenakan biaya tiket masuk. Di area makam hanya disediakan kotak amal, dimana wisatawan bebas untuk memberikan sodaqoh atau tidak.

Makam Keramat Agung Pemecutan mempunyai lokasi yang paling strategis dan akses paling baik dibandingkan dengan tiga pesaingnya.

Semua makam tersebut memiliki alat promosi yang sama yaitu promosi yang dilakukan oleh travel agent dan dari mulut ke mulut oleh wisatawan yang telah berkunjung.

Posisi keuangan antara makam-makam tersebut relatif sama. Sumber pemasukan dan persediaan dana masih sangat sedikit karena tidak adanya sumber pemasukan yang jelas. Pemasukan hanya berasal dari amal wisatawan yang berkunjung dan pungutan kepada travel agent yang membawa rombongan wisatawan.

Operasional dan sumber daya manusia makam tersebut memiliki posisi yang relatif sama. Pada saat berkunjung ke Makam Keramat Agung Pemecutan dan ketiga pesaingnya tersebut wisatawan akan melakukan do'a bersama. Setelah melakukan do'a bersama juru kunci akan menceritakan sejarah makam tersebut kepada wisatawan. Juru kunci memberikan pelayanan yang baik dan bersikap ramah kepada wisatawan. 
Makam Keramat Loloan Negara dikelola oleh Yayasan Nurul Huda. Sedangkan Makam Keramat Agung Pemecutan dan dua pesaing lainnya tidak memiliki organisasi kepengurusan. Makam Keramat Agung Pemecutan hanya dikelola oleh juru kunci secara turun-temurun. Makam Keramat Pantai Seseh di kelola oleh seorang juru kunci dan didukung oleh desa adat setempat. Makam Keramat Karang Rupit dikelola oleh seorang juru kunci.

\section{Strategi Pemasaran Segmenting}

Segmen pasar yang dimiliki oleh Makam Keramat Agung Pemecutan adalah wisatawan domestik yang mayoritas beragama Islam. Wisatawan memperoleh informasi mengenai Makam Keramat Agung Pemecutan dari teman/relasi dan travel agent.

Wisatawan yang berkunjung ke Makam

Keramat Agung Pemecutan berbentuk kelompok, baik bersama teman ataupun keluarga. Wisatawan berkunjung ke Makam Keramat Agung Pemecutan dengan tujuan spiritual.

\section{Targeting}

Target pasar Makam Keramat Agung Pemecutan dispesifikasikan ke dalam concentrated market (single segmenting) yaitu mengandalkan satu segmen pasar dan akan memfokuskan kegiatan pemasaran pada segmen tersebut. Target pasar Makam Keramat Agung Pemecutan adalah wisata pilgrim yang akan memfokuskan kegiatan pemasaran pada wisatawan yang mempunyai tujuan spiritual dalam melakukan kunjungan ke Makam Keramat Agung Pemecutan.

\section{Positioning}

Berdasarkan analisis pesaing dan segmentasi pasar yang telah dilakukan maka Makam Keramat Agung Pemecutan dapat memposisikan sebagai daya tarik wisata pilgrim yang dikunjungi oleh wisatawan dalam bentuk kelompok dengan motif kunjungan spiritual.

\section{Matriks IE}

Posisi perusahaan dapat ditentukan menggunakan matriks IE, dengan analisis total skor faktor internal dan faktor eksternal. Total skor faktor internal Makam Keramat Agung Pemecutan adalah 3,37, sedangkan total skor faktor eksternal adalah 3,53.
Dalam analisis IE tersebut Makam Keramat Agung Pemecutan berada pada kuadran I yaitu tumbuh dan membangun (growth and build). Strategi yang dapat digunakan digunakan adalah strategi yang intensif (penetrasi pasar, pengembangan pasar, dan pengembangan produk) atau strategi integratif (integrasi ke depan, integrasi ke belakang, dan integrasi horisontal).

\section{Analisis SWOT}

Untuk mengetahui strategi pemasaran yang dapat diterapkan oleh Makam Keramat Agung Pemecutan maka akan dilakukan analisis SWOT yaitu merumuskan strategi pemasaran dengan memanfaatkan kekuatan dan peluang serta meminimalkan kelamahan dan ancaman. Adapun strategi-strategi yang dihasilkan dari analisis SWOT adalah sebagai berikut :

\section{Strategi SO (Strengths, Opportunities)}

1. Mempertahankan dan meningkatkan citra Makam Keramat Agung Pemecutan. Penduduk Indonesia yang mayoritas beragama Islam dan mempunyai kebiasaan berziarah ke makam pahlawan, ulama', kyai, tokoh-tokoh Islam dll merupakan peluang yang dapat dimanfaatkan untuk Makam Keramat Agung Pemecutan. Dengan mempertahankan keramahan dan keterampilan pengelola dalam menjelaskan sejarah makam kepada wisatawan, serta meningkatkan kualitas pelayanan yang diberikan pengelola kepada wisatawan, maka akan membentuk citra yang baik bagi Makam Keramat Agung Pemecutan. Sehingga hal tersebut akan mempengaruhi wisatawan yang telah berkunjung untuk mempromosikan Makam Keramat Agung Pemecutan kepada keluarga atau temannya.

2. Membuat kegiatan promosi. Kemajuan teknologi dapat dimanfaatkan untuk mempromosikan Makam Keramat Agung Pemecutan. Pengelola dapat membuat sebuah website, akun facebook dan lainnya yang berisi tentang cerita sejarah Makam Keramat Agung Pemecutan dan keunikan lain yang dimiliki oleh Makam Keramat Agung Pemecutan sebagai alat promosi.

\section{Strategi WO (Weaknesses, Opportunities)}

1. Membentuk organisasi kepengurusan. Untuk mengembangkan Makam Keramat Agung Pemecutan maka diperlukan 
sumber daya manusia yang cukup. Pengelola Makam Keramat Agung Pemecutan dapat bekerjasama dengan desa adat setempat dengan membuat organisasi kepengurusan. Strategi ini juga akan memberikan manfaat bagi masyarakat lokal dalam operasional Makam Keramat Agung Pemecutan sebagai daya tarik wisata. Masyarakat local dapat berjualan makanan, minuman, atau souvenir di luar area makam.

2. Menaikkan nominal pungutan pada travel agent pemasok wisatawan. Strategi ini dibuat untuk menambah pemasukan Makam Keramat Agung Pemecutan. Wisatawan tetap tidak dikenakan biaya tiket, namun pengelola dapat menaikkan pungutan kepada travel agent yang membawa wisatawan ke Makam Keramat Agung Pemecutan.

\section{Strategi ST (Strengths, Treaths)}

1. Menjaga kualitas produk. Karena banyaknya jumlah pesaing yang baru muncul atau sudah lebih lama berkembang, maka Makam Keramat Agung Pemecutan harus menjaga kualitasnya. Pengelola harus mempertahankan dan meningktakan pelayanannya kepada wisatawan. Selain itu pengelola dapat membuat peraturanperaturan yang membatasi kegiatan wisatawan di area makam untuk mempertahankan kesakralan Makam Keramat Agung Pemecutan.

2. Menjaga keunikan arsitektur bangunan makam. Makam Keramat Agung Pemecutan mempunyai arsitektur yang unik. Dimana gapura masuk area makam memiliki ciri khas budaya Bali. Terdapat pohon yang disebut "taru menyan" tumbuh dari dalam makam. Batang pohon tersebut dililit dengan kain khas Bali. Dalam melakukan perbaikan makam pengelola dapat menambahkan arsitekturarsitektur lainnya yang bercirikan budaya Bali

\section{Strategi WT (Weaknesses, Treaths)}

Membentuk organisasi kepengurusan Makam Keramat Agung Pemecutan. Selama ini Makam Keramat Agung Pemecutan hanya dikelola oleh seorang juru kunci, sehingga pengelolaannya kurang maksimal. Oleh karena itu agar dapat bersaing dengan daya tarik sejenis yang memiliki pangsa pasar sama dan lebih dahulu berkembang maka Makam
Keramat Agung Pemecutan harus membuat struktur organisasi bersama desa adat setempat untuk meningkatkan system pengelolaannya sebagai daya tarik wisata pilgrim.

\section{SIMPULAN DAN SARAN Simpulan}

Makam Keramat Agung Pemecutan memiliki potensi pasar. Adapun yang menjadi potensi pasar Makam Keramat Agung Pemecutan adalah wisatawan domestik yang mayoritas beragama Islam dan berasal dari Jawa Timur, Jawa Tengah, dan Jawa Barat.

Makam Keramat Agung Pemecutan memiliki tiga pesaing yaitu Makam Keramat Pantai Seseh, Makam Keramat Loloan Negara, dan Makam Keramat Karang Rupit. Dalam analisis competitive matrix profile menyebutkan bahwa lokasi (place) Makam Keramat Agung Pemecutan lebih unggul dibandingkan ketiga pesaingnya, karena Makam Keramat Agung Pemecutan terletak di tengah kota dan akses menuju lokasi makam sangat mudah. Hal tersebut membuat Makam Keramat Agung Pemecutan menjadi lebih kompetitif dibanding ketiga pesaingnya.

Melihat potensi pasar yang dimiliki oleh Makam Keramat Agung Pemecutan dan posisinya yang lebih kompetitif dibandingkan dengan ketiga pesaingnya, maka Makam Keramat Agung Pemecutan dinyatakan layak dalam aspek pasar dan Pemasaran.

\section{Saran}

Untuk menjadi daya tarik wisata pilgrim dan bersaing dengan para pesaingnya, Makam Keramat Agung dapat melakukan beberapa strategi sebagai berikut :

1. Membentuk organisasi kepengurusan Makam Keramat Agung Pemecutan

2. Mempertahankan dan meningkatkan citra Makam Keramat Agung Pemecutan

3. Membuat kegiatan promosi

4. Membentuk organisasi kepengurusan

5. Menaikkan nominal pungutan pada travel agent pemasok wisatawan

6. Menjaga kualitas produk

7. Menjaga keunikan arsitektur bangunan makam

\section{DAFTAR PUSTAKA}

Kasmir dan Jakfar. 2003. Studi Kelayakan Bisnis : Edisi Revisi. Jakarta: Kencana Prenada Media Group. 
Jurnal IPTA

ISSN : 2338-8633

Vol. 2 No. 1, 2014

Pendit, Nyoman S. 1994. Ilmu Pariwisata Sebuah Pengantar Perdana. Jakarta: PT Pradnya Paramita.

Subagyo, Ahmad. 2007. Studi Kelayakan. Jakarta: Elex Media.

Suratman. 2001. Studi Kelayakan Proyek (Teknik dan Prosedur Penyusunan Laporan). Yogyakarta: J \& J Learning.

Zubir, Zalmia. 2005. Studi Kelayakan Usaha:

Dilengkapi Contoh Studi Kelayakan Usaha Air Minum Kemasan. Jakarta: Lembaga Penerbitan Fakutas. 